\title{
TEACHING IN DIGITAL SURROUNDINGS - STUDENTS OPINION ON DIGITAL TOOLS AND DIGITAL LECTURES
}

\author{
Marcin Fojcik ${ }^{1}$, Martyna K. Fojcik ${ }^{2}$, Lars Kyte ${ }^{3}$, Bjarte Pollen ${ }^{1}$, \\ \& Jan Ove Rogde Mjånes ${ }^{4}$ \\ ${ }^{1}$ Department of Electrical Engineering, Western Norwegian University of Applied Sciences (Norway) \\ ${ }^{2}$ Faculty of Humanities and Education, Volda University College (Norway) \\ ${ }^{3}$ Department of health and caring sciences, Western Norwegian University of Applied Sciences (Norway) \\ ${ }^{4}$ Department of Mechanical Engineering, Western Norwegian University of Applied Sciences (Norway)
}

\begin{abstract}
In today's world, education in higher education institutions needs to use digital technologies to reach students without them being in the same room as the teacher. The "classical lecture", with a teacher talking and writing on a blackboard interacting with students, has been in many ways exchanged with different digital or hybrid solutions. On one hand, it allows teachers to challenge their practices and try new ways of engaging students to learn, but on the other hand, it can be challenging to master different digital solutions in a way that ensures a clear message for the students.

When the whole world went into lockdown, the education at all levels needed to emergency transform learning in classrooms to learning through digital platforms. New structures had to be made, new routines, and new approaches. For some subjects it was not enough to move from sitting in a lecture room to sitting in front of a computer, it was necessary to develop solutions for presenting different programs or motivating students to be active, even if they were without a camera or microphone. Some teachers needed a blackboard to write and draw on while they talk, others needed to change between different programs to show different representations or purposes. In some cases, the digital lectures were synchronous, with teachers and students meeting at the same time to discuss a topic both in small and big groups, other times the digital lectures were asynchronous to give the students more time to prepare themselves and to activate their learning by giving them a responsibility to study individually (self-study).

After few months of trying different solutions, the teachers from Western Norway University of Applied Sciences (HVL) and Volda University College (HVO) have investigated the student's views on the different solutions they have experienced. The students were asked to answer an anonymous questionnaire of their opinion, views, and experiences with different digital solutions. The results were categorized and analyzed to select some tools or approaches that most of the students found either better or worse for their learning.
\end{abstract}

Keywords: Digital learning, integrated learning, students views on digital tools.

\section{Introduction}

In today's pandemic era, delivering online lectures, via video or streaming, is often the only option in higher education (Hussein et al., 2020, Lin \& Gao, 2020, Nieuwoudt, 2020). This is due to the need to temporarily close campuses, or limit student attendance. Sometimes the restriction for a meeting on campus are national, sometimes they are local, sometimes the institution themselves that decides to proceed only with online courses, and sometimes there are the students that demand access to the lessons without the need to come on campus. The frequencies of online lectures have been like never before. Both asynchronous (not real-time) and synchronous (real-time) classes are conducted at higher education institutions in Norway, by teachers from different professions. Some teachers have been teaching online for many years, with many experiences, assignments, resources, and methods to prepare and to conduct online lectures, and some are just starting, with little experience and resources.

This study asked the students about their opinions, experiences, and attitudes towards the online lectures they have had these past semesters. The research questions are: How do online lectures work one year after the pandemic has started and what are students' opinions and experiences about the lectures they have had? 
To answer these questions, the authors surveyed 1st-year students from two study lines at Western Norwegian University of Applied Sciences (HVL), campus Førde and two study lines at Volda University College (HVO). All of the participants have had a unique schedule since they started their studies, with some lectures and seminars on campus (groups of max 25 people), and some lectures and seminars online. The survey was designed to asked students with some experience in both synchronous, asynchronous, and physical/on-campus lectures, to get students to compare their experience and opinions of the different methods. In total 57 students participated in the survey. Participation in the survey was voluntary, all 1 st-year students were asked, but only about $60-80 \%$ responded depending on the study line. Not every question was answered by all the participants. Both higher education institutions have specific profession-education and the size of the groups is quite small. The lines from HVL were Automation line with 6 students participating and IT line with 9 students participating. From HVO was Teacher Education 1-7 (primary school, grades 1-7) with 22 students participating and Teacher Education 5-10 (primary and lower secondary, grades 5-10) with 20 students participating in the questionnaire.

The survey was anonymous and voluntary and had been previously examined by the Norwegian Centre for Data Surveys (NSD) and was assessed as not requiring reporting and not sensitive. No personal information was gathered about the participants. Some of the results obtained were compared with the results of a previous survey conducted before the pandemic (Fojcik \& Fojcik, 2020).

\section{Survey structure and some results}

The survey covered several aspects of learning through online lectures. Students were asked, among other things, about the self-assessment of their digital skills, the learning software used, their favorite or expected forms of lectures, exercises, and teaching methods. Other questions asked about student input. For example, if and why they use a camera in synchronous online lectures, if and why they use a microphone or chat, how they acquire study materials, what equipment and internet connection they use. Due to space constraints, only selected elements will be described in this article.

\subsection{Place/role of the teacher}

A total of 57 students responded fully or partly to the survey. They evaluated both the preferred teaching methods. The vast majority of students expect a variety of digital teaching methods - only $17 \%$ expect only classical methods.

One of the main purposes of the study was to gather students' opinions on the learning method that they preferred. Some questions in the survey asked students their perspective on the teacher's role in the learning method they liked best. The results show that most of the students expect to learn with a physically present teacher, all or some of the time. The reasons for this were mainly to explain difficult topics, to answer questions and to motivate the students, and lead the discussion by showing different examples and perspectives. These results (Fig 2) were compared with a similar study (Fojcik \& Fojcik, 2020) from before the pandemic (Fig 1), where 17 Automation students and 9 IT students participated. The largest change in student's opinion is that more students want this interaction with the teacher present, and fewer want just online lectures.

Figure 1. HVL: Lecture form according to student's needs (before coronavirus).

\begin{tabular}{|l|l|}
\hline HVL - Automation & HVL - IT line \\
\hline & \\
\hline
\end{tabular}

Figure 2. HVL: Lecture form according to student's needs (after 1 year of coronavirus).

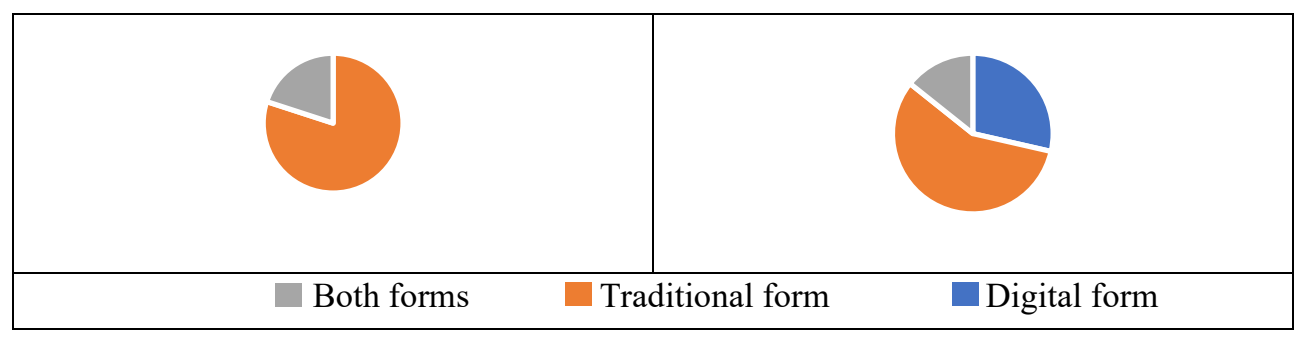


Gathering all students' opinions on what kind of lectures they perform, there is a dominance of students that want to have just physical/on-campus lectures (Figure 3).

Figure 3. Lecture form according to student's needs (after the first year of coronavirus).

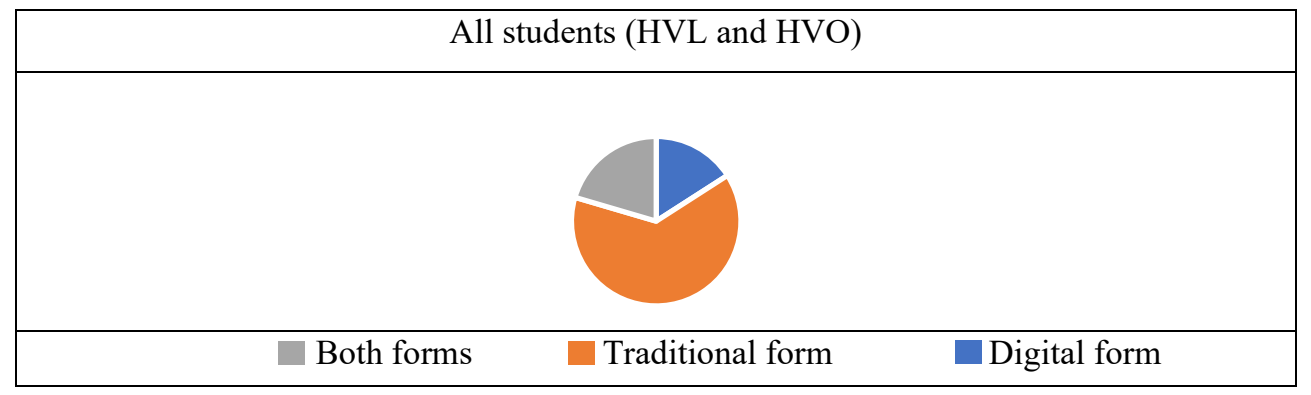

\subsection{Students motivation for learning in lectures}

Some other questions in the survey were about the motivation to learn using digital methods or comparing the motivation in different types of lectures. The survey asked the students about:

Whether they think that online lectures have less variety than on-campus lectures, and if so, why?

Whether the motivation is different: in on-campus and online lectures. What about the synchronous or asynchronous lecture?

The results show that most of the students $(66 \%)$ express that they are not motivated at all by the online lectures and some of them (13\%) express that they are partially or temporarily motivated to learn via the Internet (very divided answers, some are motivated just by asynchronous lectures while some just for synchronous when they can work in groups/breakout rooms). Only $21 \%$ of the students thought they were motivated for online lectures.

In the answers on the survey the students complained about a variety of issues that make it difficult to concentrate on learning through online lectures, and many times the disadvantages for some students were advantages for others. This is a common result when comparing these forms of online lectures (Lin \& Gao, 2020, Nieuwoudt, 2020). Students commented both the way of teaching: monotonous monologue of the teacher, looking at the screen for many hours in a raw, lack of discussion, dialogue, social elements and the technical: problem with the configuration of the equipment, inability to use it correctly both on the part of the student or the teacher or both, problems with the Internet and so on. Surprisingly, while some students in a group explained why they were motivated by asynchronous lectures, comparing them to podcasts, praise the ability to stop the video or repeat a part, or just doing the lecture when they felt well awake and well-rested. Other students from the same group complained that the asynchronous lectures were difficult to do on their own, hard to self-control, there was no interaction or discussion, the video did not answer their question or understandably explained the topic. This shows that there are many different opinions about online lectures and if or how they manage to motivate students learning.

\subsection{Preferred methods of lectures}

Students participating in this research want a teacher who will be using a variety of possible devices and different learning methods to both present the content and make it interesting and exciting for the students to participate in the lecture. Most students explained that concerning the online lectures, they do not have strong opinions about their preferences (Brockfeld et al., 2018) and that they like to have both forms; asynchronous and synchronous lectures combined. The reasons for this are interesting and sometimes in opposition to others' wishes (Nieuwoudt, 2020). Students want to have a synchronous form to have the possibility to contact a teacher, ask questions, ask about explanation or repetition. But very few of them are asking questions at all. $70 \%$ of the students from this study do not ask questions at all and 29\% do so only sometimes, in smaller groups. One possible explanation for this is that students want the possibility rather than the result. In this case, when a student knows that he or she can ask questions and get an answer from the teacher they may be contempt enough to concentrate on other things, but when the student knows that it is up to him or her to make sure everything is clear and the support is not as visible or easy to access, the maybe more distracted during the lecture. This allegation should be further research in future studies.

The survey showed that today's students expect lectures with good quality recordings, a variety of activities, and interactive forms even for online lectures - Padlet, Kahoot, or quiz. Such a recording should have both relevant subject content, a pedagogical approach and be technically good. That is another surprising result. Before and at the beginning of the pandemic the students did not pay much attention to the technical quality of the video and were satisfied as long as the content was clear (Fojcik et al., 2020), now, after a year, they much more expect a better quality of the video or at least a proficiency in using the 
equipment from the teachers. This can mean that the students are more occupied by the quality of the online lectures when they are exposed to them for longer periods, than when the videos were used as a variation in the learning process.

When students were asked to describe their ideal lectures (without thinking of practical applications), many of them answered that the absolute best would be on campus/synchronous online lectures with a variety of activities, exercises, and discussion, as well as an asynchronous video explaining the topic to watch when they are writing assignments or preparing for the exam. Some preferred to have separate videos, while others said it would be enough with a recording of synchronous or on-campus lectures/exercises. Students want to have this form to learn at their speed, with a possibility to pause and rewind forward or back or repeat some more challenging parts. One of the courses in this study records all of the lectures (both digital and on-campus), but unfortunately, the statistics from software managing video files show that most of the students will re-watch the recording only some days before the exam if they will re-watch it at all. This can again be a form for students' feeling of security, to want something just to know that it is available on-demand, but not necessary to make it a central part of learning.

\subsection{Students activity during lectures and self-regulated learning}

By analyzing the results, the authors found some tendencies in students' answers about their views on what is student's role in a lecture. One of them is that many students seemed to expect to be comfortable while learning and the feeling of comfort and security seem stronger than the feeling of learning, for some students. While describing synchronous online lectures many students express that they are not accustomed (especially when using digital media) to being involved, to showing off, to being active. They focused on things like not being seen, not disturbing the teacher, not being taken a picture of, not showing the camera, not being active, not asking questions, and generally not having any attention from the class whatsoever. The results show that when students are participating in a lecture while staying at home, many of them feel uncomfortable both by showing a part of their private home and by the way they look/have the attention during synchronous online lectures. $53 \%$ of the students in this study do not use the camera at all, $35 \%$ of the students only use the camera occasionally, (in smaller groups/when others do the same/when they are in a good mood), and only $11 \%$ of the students answered that they use the camera constantly during the online lectures.

The arguments students describe are reasonable in larger groups or publicly open lectures, but they at in some part questionable when the student meets the same group of people again and again, both in online lectures and on class lectures and the groups are less than 25 students. Another questionable factor is the lack of technical skills such as remove the background (available in many programs) or switching the microphone (mute on / mute off), or the lack of conditions or interest to find creative solutions such as preparing the learning station before the lecture, clear the presence of other people, noise and other distractions which in itself makes learning difficult. There may be many reasons why the students rather choose not to participate in online lectures than take some time to prepare their surroundings, physically or digitally.

The tendencies in survey answers show that many students largely expect a momentary solution to their challenges. Lecture - yes, but participation - no, recording - yes, but later. This may indicate an inability to cope with today's challenges or an inability to adjust to previously accepted norms of behavior. A few years ago, sitting in lectures was a necessity. Today, many people would like to avoid it. The widespread availability of video games and movies with special effects means that a "normal" lecture recording can be uninteresting. This can be a result of a reluctance to show up, to get involved, social exclusion, problems with self-regulated learning, or something else. Students may not be aware that it is significant for learning to either come ready with solutions that are suited for the conditions or take an easy way out and not participate in an online lecture. They might not know the difference, or they might think that it does not matter for them, or the feeling of comfort is more important than trying different alternative setups, or any other reason.

\subsection{Equipment and self-assessment of digital skills}

Students' answers in the questionnaire show that they have good equipment for digital learning. They all have a laptop (but many write they don't use a camera because they don't have a built-in one) and a mobile smartphone, most of them also have a desktop computer with multiple monitors at home. Besides that, about $1 / 3$ of them have a notepad/MacBook/tablet. This comes at a cost, which can be a problem, especially for a student. The students were satisfied with their equipment, but most of them explained that they used only one or two devices in lectures, both on-campus and online lectures.

Besides questions about the equipment used, the students were asked to grade their own digital skills on a 1-5 scale, where 1 was very poor, while 5 was very good. Table 1 shows the mean from each class. 
Table 1.

\begin{tabular}{|l|c|}
\hline \multicolumn{1}{|c|}{ Class } & Mean of students self-assessment \\
\hline HVL Automation & 2,6 \\
\hline HVL IT & 4,3 \\
\hline HVO Teacher education 1-7 & 4,1 \\
\hline HVO Teacher education 5-10 & 3,6 \\
\hline
\end{tabular}

Unfortunately, comparing students' self-assessment of digital skills with other answers on the questionnaire, there were many uncertainties about their actual skills. This manifests itself in the way they describe the programs they use, the technical problems they have, the quality of the Internet connection, etc...). Another surprising result is that when asked about their Internet connection, most of the students said to have broadband connections of quite high speed, but students who evaluate their digital skills as very good, answer: "good quality", those students who consider themselves less competent answer: „50/50Mb/s” or ,300Mb/s". These descriptions show the ability to name and define certain elements and do not coincide with self-assessment or the self-assessment can be interpreted in different ways (Fojcik et al., 2017). It is often, but of course not always, more an opinion of oneself than an assessment of one's abilities.

\section{Discussion and conclusion}

Most of the students in the selected subjects taught at HVL and HVO participated in the survey, but both schools are rather small, so the survey is not fully quantitatively representative. The results can only show a trend in both places.

This study tried to answer the research questions: How do online lectures work one year after the pandemic has started and what are students' opinions and experiences about the lectures they have had?

The results show that the students seem to have specific expectations about the different methods of lectures, they know what they like and what they dislike, but their answers are often contradicting both within a class, and with students themselves. Some students like asking questions, use the camera, and participate actively in the lectures, while others preferred to learn at their own speed, with videos and less interaction, or just without any camera or microphone so that no one can notice them. Most students in this study seem to have struggled with motivation for online lectures, and the social connection with other students. Another result is that some of the students comment on the insufficient technical knowledge of teachers; errors in recording, problems with sound, image, graininess, illegibility of text, image freezing, constant switching, etc.

The authors have noticed multiple times that the process of learning is much more effective when the teacher is a part of the learning process and can guide and support the students in their learning. While students comment on things like "they would not want to disturb" or "they want to do this themselves", which often may be a good idea, but the students should know that teachers' role is to guide and support so that they are not completely on their own.

\section{References}

Brockfeld, T., Müller, B., \& de Laffolie, J. (2018). Video versus live lecture courses: a comparative evaluation of lecture types and results. Medical Education Online, 23(1), 1555434.

Fojcik, M., Fojcik, M. K. (2020). Digitalisation of higher education - teachers and students experience. Proceedings of International Conference on Education and new Developments 2020 (END2020), 26-27 June. InScience Press

Fojcik, M., Fojcik, M. K., Hegland, P. A., Kyte, L., Midtbø, T. G., Pollen, B., Sande J, Sande, O. (2020). Praktisk digitalisering av høgskuleundervising. I Digital samhandling (pp. 321-335).

Fojcik, M., Galek, J. og Fojcik, M. K. (2017). IKT kompetanse blant studenter. Er vi klare for fremtiden? Proceedings of MNT-conferance 2017, 30-31 March, Oslo.

Hussein, E., Daoud, S., Alrabaiah, H., \& Badawi, R. (2020). Exploring undergraduate students' attitudes towards emergency online learning during COVID-19: A 9+case from the UAE. Children and Youth Services Review, 119, 105699.

Lin, X., \& Gao, L. (2020). Students' sense of community and perspectives of taking synchronous and asynchronous online courses. Asian Journal of Distance Education, 15(1), 169-179.

Nieuwoudt, J. E. (2020). Investigating synchronous and asynchronous class attendance as predictors of academic success in online education. Australasian Journal of Educational Technology, 36(3), $15-25$. 